\title{
Infection of a Homogeneous Population by a Known Bacterium
}

Arthur Maknenko

University of South Florida

Advisors:

Arcadii Grinshpan, Mathematics and Statistics

Gordon Fox, Integrative Biology

Problem Suggested By: Gordon Fox

Follow this and additional works at: https://digitalcommons.usf.edu/ujmm

Part of the Mathematics Commons

UJMM is an open access journal, free to authors and readers, and relies on your support:

Donate Now

\section{Recommended Citation}

Maknenko, Arthur (2009) "Infection of a Homogeneous Population by a Known Bacterium," Undergraduate Journal of Mathematical Modeling: One + Two: Vol. 1: Iss. 2, Article 6.

DOI: http://dx.doi.org/10.5038/2326-3652.1.2.6

Available at: https://digitalcommons.usf.edu/ujmm/vol1/iss2/6 


\title{
Infection of a Homogeneous Population by a Known Bacterium
}

\begin{abstract}
In order for the development of antibiotics and vaccines to be successful, the lifecycle and infection pattern of a pathogen must be studied well. In this paper, we study the rate of replication and the pattern of infection in a homogeneous population, which may or may not have an effective immunity or immunization program against the pathogen. We utilize three functions: one will determine the rate with which the pathogen replicates; the second will show the result of an infection by a single individual of a susceptible population without a removal rate; and the third will include the removal rate and its dependent factor, intensity.
\end{abstract}

\section{Keywords}

Neisseria meningitidis, Streptococcus pneumonia, Haemophilius influenza

Creative Commons License

(c) (i) (अ)

This work is licensed under a Creative Commons Attribution-Noncommercial-Share Alike 4.0 License. 


\section{Problem Statement}

What conditions allow a single infected person to create an epidemic in a homogeneous population of susceptible individuals if the pathogenic organism replicates quickly and has a sequenced genome that is littered with other bacterial genes?

\section{Motivation}

Many rapidly replicating bacterial pathogens are present within human beings, especially in the upper respiratory tract. One particular bacterial organism Streptococcus pneumonia —which kills approximately 1.1 million people worldwide and is one of the top ten causes of death in the US (JB 5709)—outcompetes Haemophilius influenza and Neisseria meningitidis (all three are commonly found in patient samples) by inhibiting their growth via a gene-regulated excessive production of Hydrogen Peroxide and a fast duplication rate in nutrient-rich conditions, such as blood (JB, 5713). Therefore, it is an appropriate candidate for analysis in this paper, as it has the potential to cause a true epidemic outbreak.

\section{Mathematical Description and Solution}

In this paper, three equations will be utilized. One will demonstrate that under normal bodily temperature $\left(37^{\circ} \mathrm{C}\right)$ and nutrient rich conditions the virulent strain of the $S$. pneumonia will double every 30 minutes and will produce a large colony capable of infecting other susceptible individuals (children and young adults) within hours (TOTB, 04/30/09). The second-an integral equation of a simple epidemic model without a removal rate-will demonstrate that a single infected individual can spread the pathogen relatively quickly among the susceptible, even those who are not in direct contact with the infected person. The third equation will implement a removal rate estimation, which will determine whether this outbreak will grow into a full epidemic and what its overall intensity will be.

\section{Bacterial Population Growth}

The population growth, $d P / d t$, of the $S$. pneumonia colony can be modeled by

$$
\frac{d P}{d t}=\frac{3000}{1+t / 4}
$$

where $t$ is the time in hours (CETF, 360). The initial population (at $t=0$ ) consists of 1000 bacteria. The integral of the function yields the population, $P(t)$, as a function of time:

$$
P(t)=\int \frac{3000}{1+t / 4} d t
$$

Making the substitutions $u=1+1 / 4 t$ and $d u=1 / 4 d t$, we obtain 


$$
P(t)=12000 \ln \left|1+\frac{t}{4}\right|+C
$$

where $C=1000$. Therefore,

$$
P(t)=1000\left[12 \ln \left(1+\frac{t}{4}\right)+1\right]
$$

\section{$\underline{\text { Spread of Infection }}$}

Assume that the population initially contains one infected individual; let $x$ represent the number of additional individuals infected. The second equation reflects the hypothesis that the infection spreads at a rate proportional to the product of the infected population, $x+1$, and the remaining uninfected population, $n-x(\mathrm{CETF}, 560)$ :

$$
\frac{d x}{d t}=k(x+1)(n-x)
$$

where $k$ is the constant of proportionality and $n$ represents the total population. Refer to the Appendix for a full solution. Two graphs for different populations $(n=10$ and $n=100)$ are also included in the Appendix to illustrate the solution to this equation.

\section{$\underline{\text { Removal-Rate Estimation }}$}

If immunity or an immunization program is present in the population described above, then according to the famous equations of Kermack and McKendrick (EM, 28) the number of susceptible individuals, $y$, is related to the number, $z$, of immune individuals and the number, $x$, of infected individuals according to the following equations:

$$
\begin{gathered}
\frac{d y}{d t}=-\beta y x \\
\frac{d x}{d t}=\beta y x-\gamma x \\
\frac{d z}{d t}=\gamma x
\end{gathered}
$$

where $\beta$ is the constant infection parameter and $\gamma$ is the constant removal rate.

Then, $d y / d z=-\frac{\beta}{\gamma} y=-x / p$, where $p=\gamma / \beta$ is the relative removal rate. $\beta, \gamma$, and $p$ are determined by the particular outbreak (EM 29). The intensity, $\iota$, of an epidemic is defined by

$$
\iota=\left[1-\frac{p}{N}\right] \times 100
$$




\section{Discussion}

Using the model for bacterial population growth, we may compute the populations at varying times:

$\mathrm{P}(1 / 2)=1000[12 \ln (9 / 8)+1] \approx 2413$ bacteria

$\mathrm{P}(5)=1000[12 \ln (9 / 4)+1] \approx 10731$ bacteria

$\mathrm{P}(10)=1000[12 \ln (7 / 2)+1] \approx 16033$ bacteria

$\mathrm{P}(15)=1000[12 \ln (19 / 4)+1] \approx 19698$ bacteria

We conclude that within 15 hours 1000 bacteria will replicate to a colony numbering approximately 20000 . Therefore, a single infected person can begin infecting others within the first day of contact.

If no immunity or an immunization program is present in a susceptible population, then the newly duplicated bacteria will infect the entire susceptible population. In other words,

$$
\lim _{t \rightarrow \infty} x=n
$$

The graphs demonstrate that the single infected person has the potential to infect the whole population without direct contact will all of the susceptible members in a specific timeframe.

The $\mathrm{p}$ value (relative removal rate) has two important implications for the progress of an outbreak into a full epidemic:

a. If $p<y_{0}$ (initial number of susceptible persons), then the infected population will increase until $x=y$ after a time measured in days as predicted by the second equation. (EM, 33).

b. The intensity ( 1 ) of an epidemic:

$$
\begin{gathered}
\iota=[1-(4 / 10)] 100 \%=60 \% \\
\iota=[1-(3.3 / 10)] \cdot 100 \%=67 \%, \\
\iota=[1-(3 / 10)] \cdot 100 \%=70 \%
\end{gathered}
$$

as soon as $n \geq 3 p$ an epidemic will occur (EM, 35).

\section{Conclusions and Recommendations}

Several important facts are evident about the spread and the control of the discussed diseasecausing bacterium: 
1. A pathogen that has a high-rate reproduction cycle has the potential to infect the total population, in seven days for $n=10(\mathrm{x}=9.95)$ and in nine days for $n=100(\mathrm{x}=99.5)$ if no form of immunity is present.

2. The value of $p$ (relative removal rate) indicates the intensity of an outbreak. If it is maintained, then the minimal infection that enters the population will not progress into an epidemic because the pathogen will not find susceptible hosts in which to thrive and many susceptible persons will be immunized.

3. If $p<x_{0}$ (initial value of susceptible persons), then the infected population (y) will increase until $\mathrm{x}=\mathrm{y}$. This can be avoided via vaccination of the susceptible population prior to the infection. For example, if $50 \%$ of the population is vaccinated, then $\mathrm{p}$ can never be less than $\mathrm{x}_{\mathrm{o}}$ and the intensity of the outbreak cannot reach the epidemic levels of $67 \%$.

4. Considering that the genome (total genetic code of an organism) S. pneumonia has been sequenced and the genes that control the "cell division, DNA replication and repair, translation, cell wall biosynthesis, catabolic and biosynthetic pathways" are known (JB, 5713), along with the polysaccharide capsule generation, which makes the bacterium able to cause severe disease, one possible recommendation can be to create antibiotics and vaccines that target these specific elements and not simply the physiology of the bacterium.

\section{References}

Daley, D. J. and Gani, J. "Epidemic Modeling: An Introduction." Cambridge University Press: Cambridge, UK: 1999. 28, 29, 33, 35.

Larson, Hostetler, Edwards. "Calculus: Early Transcendental Functions." $4^{\text {th }}$ Ed. Houghton Mifflin Company: Boston, MA: 2007. 360, 560.

Lilly, Eli. "Genome of the Bacterium Streptococcus pneumonia Strain R6." Journal of Bacteriology. Vol. 183, No. 19. American Society of Microbiology: October, 2001. 5709, 5713.

Todar. "Todar's online Textbook of bacteriology: Streptococcus pneumonia." 04/30/2009. http://textbookofbacteriology.net. 


\section{Appendix}

\section{Solution of the Bacterial Population Growth Equation:}

$$
\frac{d x}{d t}=k(x+1)(n-x)
$$

$n=$ susceptible persons

$x=$ infected persons

$k=$ the rate at which the susceptible persons become infected

$t=$ time

$$
\begin{gathered}
\int \frac{1}{(x+1)(n-x)} d x=\int k d t \\
\frac{A}{x+1}+\frac{B}{n-x}=\frac{1}{(x+1)(n-x)} \\
A(n-x)+B(x+1)=1 \\
(B-A) x+B+A n=1 \\
\Rightarrow B=A \text { and } A+B n=1 \\
\Rightarrow A+A n=1 \Rightarrow A=\frac{1}{1+n} \Rightarrow B=\frac{1}{1+n}
\end{gathered}
$$

Therefore,

$$
\begin{gathered}
\int \frac{1}{(x+1)(n-x)} d x=\frac{1}{1+n} \int\left(\frac{1}{x+1}+\frac{1}{n-x}\right) d x \\
=\frac{1}{1+n}(\ln |x+1|-\ln |n-x|)=\frac{1}{1+n} \ln \left|\frac{x+1}{n-x}\right| \\
\text { and so } \frac{1}{1+n} \ln \left|\frac{x+1}{n-x}\right|=k t+C .
\end{gathered}
$$

When only a carrier is present, $x=0$ and $t=0$, which implies that

$$
C=\frac{1}{n+1} \ln \frac{1}{n}
$$




$$
\begin{gathered}
\frac{1}{1+n} \ln \left|\frac{x+1}{n-x}\right|=k t+\frac{1}{n+1} \ln \frac{1}{n} \\
\ln \frac{x+1}{n-x}=(n+1) k t-\ln n \Rightarrow \frac{x+1}{n-x}=g:=\frac{e^{(n+1) k t}}{n} \\
x+1=g n-g x \Rightarrow x(1+g)=g n-1 \Rightarrow x=\frac{g n-1}{1+g} \\
x=n \frac{e^{(n+1) k t}-1}{n+e^{(n+1) k t}}
\end{gathered}
$$

The following charts give the growth of the infected population with time for two populations, $\mathrm{N}=10$ and $\mathrm{N}=100$, corresponding to $k=0.1$ and $k=0.01$, respectively.

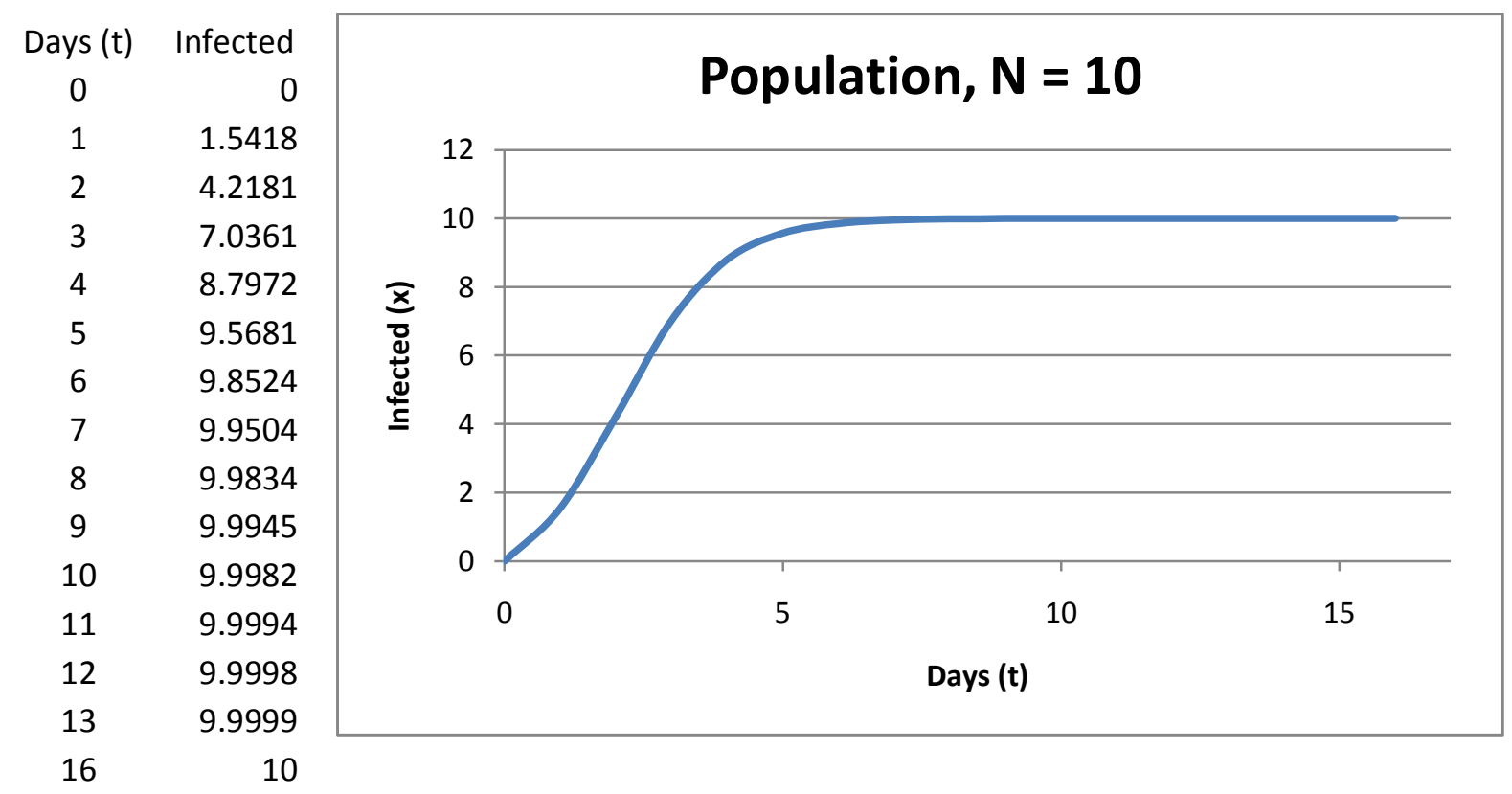




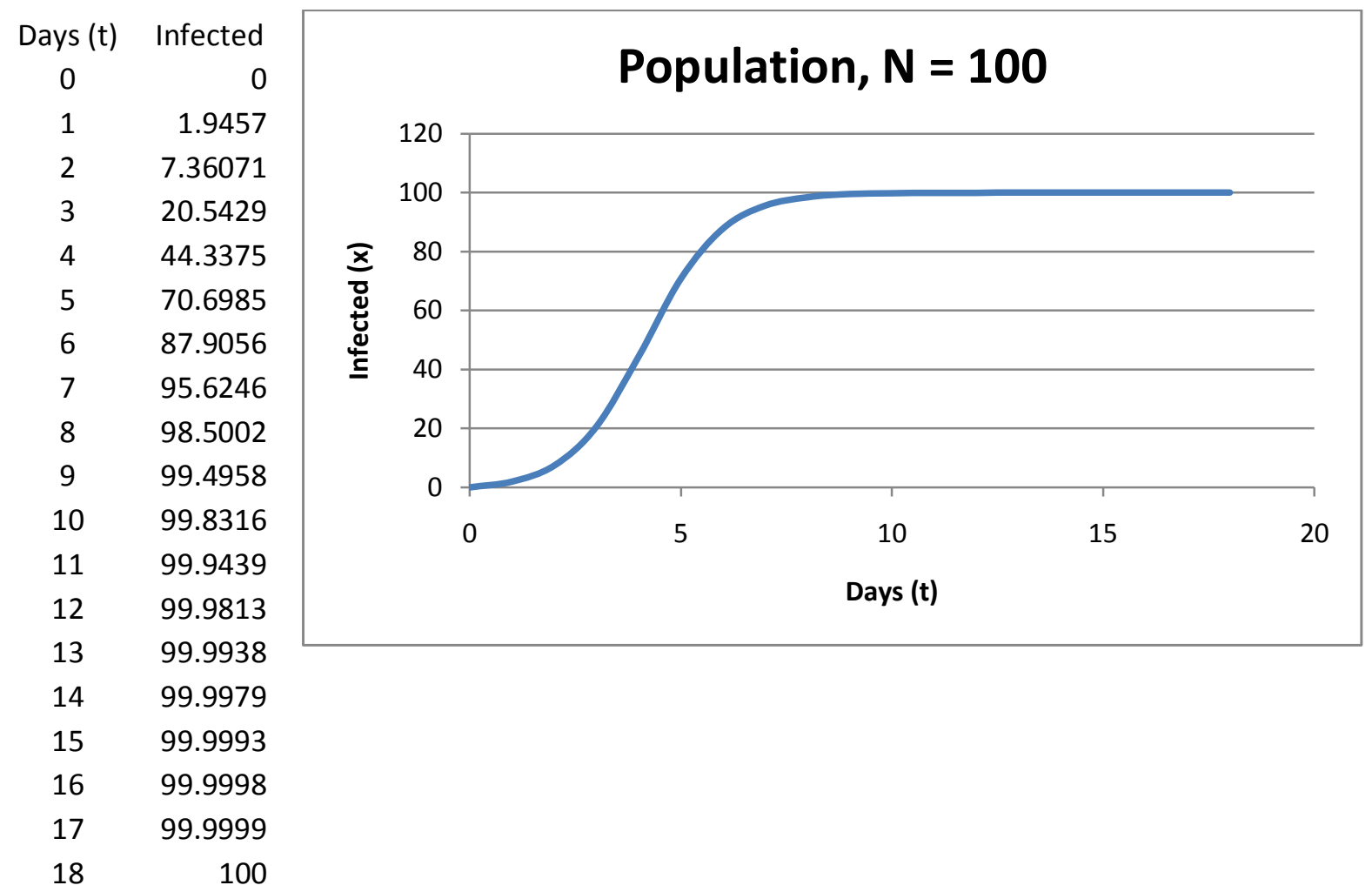

